* Corresponding author

Phone +42155602 2716

E-mail address:miroslav.badida@tuke.sk

(prof. Dr. h. c. Ing. Miroslav Badida, PhD.)

Article information

Article history: AMS-Volume16-No.1-00137-12

Received 16 January 2012

Accepted 11 February 2012

\section{Teoretical Basis and Application Possibility of Radiosity Methods for Lighting Researches}

\author{
Miroslav Badida* , Ružena Králiková, Katarína Kevická
}

Department of Environmental, Faculty of Mechanical Engineering, P. Komenského 5, 04200 Košice, Slovak Republic

\section{BIOGRAPHICAL NOTES}

Miroslav Badida, Dr.h.c. prof. Ing. PhD. He is a graduate of Mechanical Faculty of Technical University of Košice. His scientific and research work focuses on the field of environmental engineering. An accent is put on the issue of environmental management systems, ecologization of products and their production and life cycle analysis of products. Lately his attention is paid on research in the field of physical factors of working and living environment.

Ružena Králiková, doc. Ing. PhD. received M.S. degree in mechanical engineering form Technical University of Košice, Slovakia in 1980 and PhD. degree in 1996. She is an associated profesor of the Department of Environmental Sciences at the Faculty of Mechanical Engineering at the Technical University of Košice, Slovakia from 2001. Her researche interests include environmental monitoring, engineering and management, working environment, especially lighting and microclimate conditions of environment. She has autored of the monography, 6 textbooks and more than 100 journal and conference papers on this topics.

Katarína Kevická, Ing. Is a PhD. student of the Departement of Environmentalistics at Faculty of Mechanical Engineering at Technical University of Košice. She received B.Sc. and M.Sc. degree in the field of Engineering Environmental Protection at the same university in 2007, and 2009, respectively, and received Medal of Dean for excellent student (2009). Her current field of interest is focused on the area of lighting technology, such as measurement and evaluation of lighting, simulation of lighting and reducing energy consumption of lighting systems.

\section{KEY WORDS}

Working Environment, Light, Lighting Microclimate, Simulation

\section{ABSTRACT}

The article deals with designing internal artificial lighting as part of the work on the environment, which is subject to certain rules, derived from the nature of lighting. Good lighting exerts an impact on visual comfort - which contributes to overall psychological well-being, and indirectly also to the quality and productivity of performance, to reliability, and to visual performance - and which must be maintained, especially in long-term operations and in adverse conditions, to ensure quality of work and safety. One of the most frequently raised requirements for project design nowadays is speed; therefore a successful project cannot be done without good application software. The result is hundreds of drawings and various other outputs, which, without good software, cannot be handled within a short period of time. Modeling and simulation technologies are tools to streamline the presentation and assess the risks for the implementation. 


\section{Introduction}

In terms of quantity of information a person registers $80 \%$ to $95 \%$ of all information visually in the work. Primary role in creating the work environment becomes to ensure optimal conditions of vision and ensure a safe working environment. Visibility must therefore be seen as a precondition for the realization of high quality, safe and reliable operation work.

Designing internal artificial lighting as part of the work or the environment is subject to certain rules, which derive from the nature of the illumination (KIvac, 2008). Good lighting has an impact on:

- visual comfort - which contributes to the overall psychological well-being, and indirectly also the quality and productivity of its activities,

reliability,

- visual performance - which has to be maintained especially in long-term operations and in adverse conditions,

- quality work,

- security.

Lighting of workplaces put on light-technical solution to the following requirements:

- sufficient value lighting horizontal and vertical for a particular type of work performed,

appropriate distribution of brightness in the area,

- suppress the creation of glare and protect against,

- satisfactory psychological action of the color of the light and color of administration,

- appropriate color change environment,

- stability lighting,

- reasonable uniformity,

- suitable orientation of the impact of light on the desktop. (Smola, 2003).

In compliance with all quantitative and qualitative parameters of illumination, we must design a lighting system based on the principles of maximum performance (Silion et al., 1994). Economize electricity can especially selecting a new generation of lamps, i.e. long life and high efficiency. By lighting systems with a streamlined operation, regulation and management of lighting can also contribute significantly to energy savings.

\section{Light-technical Projects - Methodical Procedure}

Project of lighting system is a complex and labo- rious task that requires not only technical knowledge but also knowledge of architecture, production and physiology of vision. The role of the designer is not only a select type of solution, this task is often complex, may have a research character, leading to the development and manufacture of lighting systems testing, analysis and findings of optimum lighting conditions of employment and area as a whole.

To develop a quality project of lighting system, we shall have in hand construction, technological and health technical drawings illuminate the object and also be familiar with the technology or the purpose of the space. In addition to the quantitative and qualitative parameters of lighting working area or the surrounding area should be well respected lighting system fault-free functions, the possibility of a comfortable handling luminaries and lighting efficiency. (Smola et al., 2005).

Among the fundamental base of light-technical project includes:

- room dimensions and design of the room,

- purpose room,

work which is mostly performed in the area,

- size and layout of work equipment and furniture,

- deployment of staff,

- color and reflectivity factor of furniture and ceiling installations,

- special requirements for the color of light,

- type of environments (explosive, dusty, wet, etc..),

- finish of area, coating the walls, ceiling, floor type,

- kind of the power current system,

- an annual period of use of lighting systems,

- rate for electricity consumed,

work time, variation.

Project of lighting system is divided into lighttechnical, electric and budget section. Light-technical part of the interior lighting consists basically of two main parts:

- technical reports,

- drawing section.

Technical report includes:

- description of the illuminating area,

- demands on visual activity, and thus the determination of the category and work class,

- lighting values,

- qualitative indicators lighting (brightness distribution, direction of light, flare, lighting, durability, color and color submissions, etc..), 
- type of lighting system,

- choice of lamps and lanterns,

- computational methods used and the specific calculations of lighting,

- color adjustment immediate surroundings,

- assistant addressing, security, and replacement of emergency lighting,

draft operation and maintenance of lighting equipment,

\section{- economic recovery proposal.}

\section{Drawing section contains:}

- footprints and cuts of lighting facilities,

- prescribed value of lighting on certain points and certain values lighting quality parameters,

- electrical distribution, involvement and control of lighting systems,

- deployment lamps, their specifications and with an indication of the light resources,

- isolines diagrams and marking control points by which it was assessed agent glare.

In addition to the documents belonging to the set of drawings of implementing the various elements of design drawings, light installations, drawings, complete assembly of nodes and connections of typical components, the contract drawings for the execution of the cost and implementation of the proposed lighting.

\section{Modeling of Light-technical Parameters In the past there were three basic types of light-tech- nical models (Budak et al., 2006):}

- calculation (without taking into account the actual dimensions, with tables),

- accurate (for models in the scale 1:1),

- using of mock-ups that generate a display similar to visual perception designed lighting system.

Currently, in the light-technical modeling applies a different approach, which is based on computer visualization of spatial scenes designed lighting system. In this case, the light-implemented calculations with the given precision without the use of costly physical models (Budak et al., 2006). The computer visualization, whose goal is to see the photo, is often described in detail the model and simulates the propagation of light in space.

Modern visualization programs can reproduce the brightness, color and surface structure of the complex three-dimensional space rather realistic, since in the calculations include inter reflection of light between surfaces in space and in many op- tical effects arising in the day, an artificial joint or lighting. Simulation methods are based on classical optical, thermodynamic, respectively light-technical models of the spread of radiation.

\section{Simulation Methods}

There are two basic methods used in computer simulations luminous environment, namely Monte Carlo method, which does apply technology tracking light beams (ray tracing, this name is used for follow-up of beams, also used the term "ray casting" sending light beam when a beam of light comes from the light source), and radiation (also radiosity). From a physical point of view both methods are similar, the difference lies in algorithmization. The method of monitoring the beam has a very small spot stochastic manner (results of re-calculation may differ slightly). The radiation method of working with larger surfaces deterministically (repeated calculation results are always the same) (Rybar, 2001)

\subsection{Simulation Monte Carlo Method and the Calculation of Direct and Indirect Lighting}

Were initially considered only spectacular reflections of light in a manner subsequently applied probability calculations and other components of illumination. The furnished rooms with surfaces that have different optical properties, with the advantage of the stochastic (probability) light calculation, often referred to as the Monte Carlo method. In general, this method is one of the operational methods of research used for the simulation of technical, economic and social situations (Rybar, 2001). The method works with random numbers obtained by e.g. generation computers. There are a number of variants of this method.

Generally, these methods use a large number of random light beams or posted particles bearing energy. Their movement in the area subject to physical laws and to monitor. Accurate calculation could be done if it has been shown to follow the path of each photo, which is of course a number of reasons. However, if accidentally sends a sufficient number of rays (particles), e.g. 50 million, will also correspond to the calculation lighting high demand for accuracy. As the monitors spread of light from the source to the environment, usually talking about the method of monitoring particles (Fig. 1a).

In terms of computer graphics is ray tracing in the direction of the light source to the observer's eye or 
camera lens onerous. Quantity rays are "lost" before the eye reaches the observer (Smola et al., 2005). It is therefore frequently used method of tracing rays (Fig. 1b) when the monitor path of light rays in the direction of the observer to the light source. In this way, the algorithms take into account the particles that are most involved in the lighting of the scene seen observers. In this case, it is place lighting proportionately dependent on the number of particles of light, which it hit, and the density of luminous flux carried by each of these particles.

The method of tracing rays in the direction of the observer sends through each point on the display screen (pixel) virtual beam of light and tested to its intersection with all objects in that space. Finds the nearest intersection, which is a visible place on the stage. Generate additional rays. Towards the light source is a transmitted ray to determine whether a visible place overshadowed some objects. As the surface is shiny object mirror, a mirror reflection of the primary beam. If the surface is transparent, open beams representing the light reflection and refraction by the optical properties of transparent material. As the surface is non-transparent, generating the beams (often more than 100) mimic light reflection from the surface.

In the case where the primary location of the intersection of the beam with a certain object in space illuminate some of the light sources (or a mirror reflection of a certain material), is calculated its lighting respectively brightness. In computer graphics for this lighting uses the term direct lighting unlike total lighting containing the contribution reflected light, which in this field of science called global lighting.

For each secondary beam is to determine the nearest intersection, and the process is repeated until a beam leaves the room or the amount of light (or brightness), which represents the imaginary beam, falls below a selected value. In some algorithms, the beam monitor, until the eye returns to the virtual observer, or are considering only the specified number of reflections. In this way, the model geometry of the space while its synthetic (color) display.

In computer memory to store maps and direct the overall lighting, which is further processed to achieve a smooth transition of Shadows, in order to describe optical phenomena, etc.

Location, type, size, and light-technical properties of light sources and surfaces in space are in the computer simulation of light environment known. With the primary beam is detected, whether the intersection of the individual beams with surfaces, visible light sources. In places illuminated directly calculate their direct lighting, respectively initial brightness. In places that are lighting only part of the light source, a partial obscuration. This issue is addressed in the simulation calculations in different ways. One solution is to send rays of these places at random in the direction of the light source while shielding these rays will be proportional to the degree of shading of the site.

In principle, beam tracing technique solves the following integral equation (1) the energy balance of each nearly all the same on surfaces in space (Rybar, 2001).

$$
L_{r}\left(\theta_{r}, \phi_{r}\right)=L_{e}\left(\theta_{r}, \phi_{r}\right)+\iint L_{i}\left(\theta_{i}, \phi_{i}\right) . \rho_{b d}\left(\theta_{i}, \phi_{i}, \theta_{r}, \phi_{r}\right) \cdot\left|\cos \theta_{i}\right| \cdot \sin \theta_{i} . d \theta_{i} . d \phi_{i}
$$

where: $\boldsymbol{\theta}$ - polar angle measured from the surface at normal levels, $\boldsymbol{\varphi}$ - azimuthally angle surface at normal levels, $\boldsymbol{L}_{\mathrm{e}}\left(\boldsymbol{\theta}_{\mathrm{r}^{\prime}} \boldsymbol{\varphi}_{\mathrm{r}}\right)$ - its own radiation (as is the area's primary source of radiation) $\left[\mathrm{W} \cdot \mathrm{sr}^{-1} \cdot \mathrm{m}^{-2}\right]$,

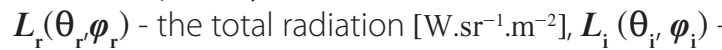
incident radiation $\left[\mathrm{W} . \mathrm{sr}^{-1} \cdot \mathrm{m}^{-2}\right], \rho_{\mathrm{bd}}\left(\theta_{\mathrm{i}^{\prime}} \boldsymbol{\varphi}_{\mathrm{r}^{\prime}} \theta_{\mathrm{r}^{\prime}} \boldsymbol{\varphi}_{\mathrm{r}}\right)$ - twoway distribution of reflectivity function $\left[\mathrm{sr}^{-1}\right.$ ].

\subsection{Radiation Methods and Radiation Equation}

Although the ray tracing algorithm (raytracing) deflects a perfect record on the mirror reflectivity and modeling undispersional refractonal transparency, but this algorithm has a shortcoming. And while that does not take into account the physical laws of some important visual effects, for example stain shade, the influence of reflection of light from another object. It is due to the fact that raytracing only monitors the final number of rays emanating from the observer's eye. This failure is trying to remove the radiation method. (Chen et al., 1991) Radiation method can be seen as a generalization of methods to monitor the beam. In this method assumes that all surfaces are ideal primary or secondary diffuse light sources (Fig.1c) (Smola, 2003), or combination of sources. The advantage of this method in terms of visualization, and algorithm development is that the surfaces of lightning calculated independently of the direction to simulated scene (Silion et al., 1994). 


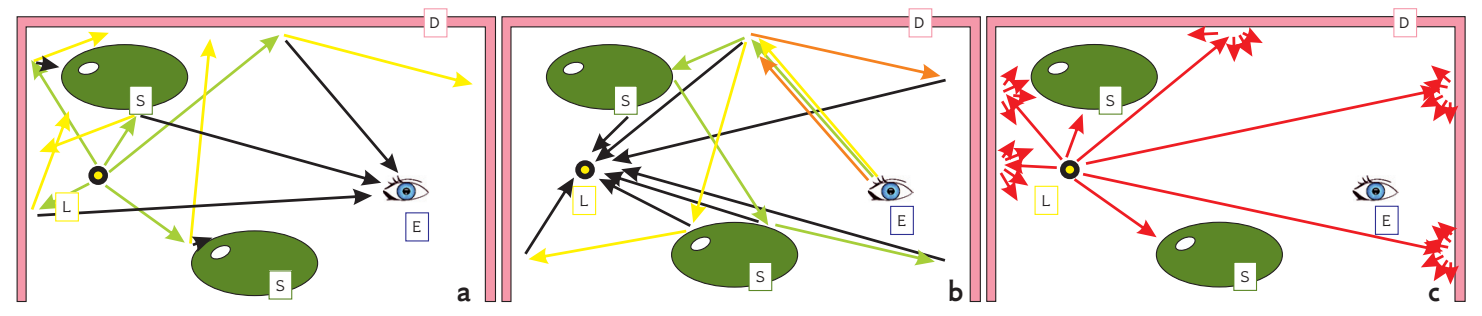

Fig. 1: Behavior of light rays in simulation methods. $a$ - the method of ray casting (Monte Carlo), $b$ - ray tracing method (Monte Carlo), c-radiation method. D - Wall space S-lighting operator, L-light source, E-Observer

The beginnings of the radiation methods are dated from 1984, mainly by contributing authors M.F.Cohen and P. Greenberg. Since this method is very demanding on the computer begin to enforce in practice until now.

Radiation method (Radiosity method) is based on the principles of the spread of light energy and the energy balance. This method, unlike conventional rendering algorithms, first interaction determines any action in light of the various independent views. Then one or more views is calculated by defining a visible surface interpolation shading.

In the algorithm for shading of the light sources are always considered independently from the surface to light. In contrast, the radiation method allows any surface emit light, ie, all light sources are modeled naturally as an active surface. Consider the distribution environment for the final number of $n$ discrete surfaces (patches), each of which has the final size and emits and reflects light evenly across its surface. Sets therefore consists of surfaces, acting also as light sources and reflective surfaces such as creating a closed system. If we consider each area of the opaque of Lambertian diffuse emitter and reflector, then applies for the area and because of the energy conservation equation (2):

$B_{i}=E_{i}+p_{i} \sum_{1 \leq j \leq n} B_{j} F_{j-1} \frac{A_{j}}{A_{i}}$

where: $\mathrm{B}_{\mathrm{i}}, \mathrm{B}_{\mathrm{J}}$ - the intensity of radiation (radiation) areas $i$ and $\mathbf{j}$, measured in units of energy per unit area $\left(\mathrm{W} / \mathrm{m}^{2}\right)$, Ei - energy of light radiated from the surface $s$ has the same dimension as the radiation, $\mathrm{p}_{\mathrm{i}}$ - the reflection coefficient (reflectivity) is the dimensionless area ia, $\mathrm{F}_{\mathrm{j}-\mathrm{i}}$-configuration dimensionless factor (form-factor), which specifies the energy leaving the surface ja incoming area and taking into account the shape, relative orientation of both areas as well as the presence of any areas that could mislead. The configuration factor takes its values from interval $\langle 0.1\rangle$, while the fully covered surface takes the value $0, A_{i}, A_{j}$ - surface levels $i$ and $j$.

Equation (2) shows that the energy leaving the unit part of the surface is the sum of light emitted by a reflection. Reflected light is calculated by multiplying the reflection coefficient and the amount of incident light. Incident light is on the contrary, the sum of the light leaving the whole area, as part of the light which reaches the receiving unit content area. $\mathrm{B}_{\mathrm{j}} \mathrm{F}_{\mathrm{j}-\mathrm{i}}$ is the amount of light leaving the unit and content area and the incident on the entire space of $\mathrm{A}_{\mathrm{i}}$. It is therefore necessary to multiply the equation of the ratio and / $\mathrm{A}_{\mathrm{i}}$ for the determination of light, leaving the entire incident and also surface to surface $A_{i .}$. (Cohen et al., 1985)

Between configuration factors in the diffuse me-

$A_{i} F_{i-j}=A_{j} F_{j-i}$

dium is a simple relationship:

By simplifying equation (2) using equation (3) we $B_{i}=E_{i}+p_{i} \sum_{1 \leq j \leq n} B_{j} F_{i-j}$

obtain the equation:

Subsequent treatment we get the equation in the

$$
B_{i}-p_{i} \sum_{1 \leq j \leq n} B_{j} F_{i-j}=E_{i}
$$

form:

The interaction of light between surfaces can be ex-

$$
\left[\begin{array}{cccc}
1-p_{1} F_{1-1} & -p_{1} F_{1-2} & \ldots & -p_{1} F_{1-n} \\
-p_{2} F_{2-1} & 1-p_{2} F_{2-2} & \ldots & -p_{2} F_{2-n} \\
\cdot & \cdot & \ldots & \cdot \\
-p_{n} F_{n-1} & -p_{n} F_{n-2} & \ldots & 1-p_{n} F_{n-n}
\end{array}\right]\left[\begin{array}{c}
B_{1} \\
B_{2} \\
\cdot \\
B_{n}
\end{array}\right]=\left[\begin{array}{c}
E_{1} \\
E_{2} \\
\cdot \\
E_{n}
\end{array}\right]
$$

pressed in matrix form (Silion et al., 1994):

Note that must be taken into account the contribution of surface reflected on his own power (which may be hollow, concave). Thus, in general, each 
term on the diagonal, not necessarily equal the first Equation (6) must be solved for each group of wavelengths of light in the model, since pi and Ei depend on the wavelength. Form factors are independent of wavelength and are solely a function of geometry, therefore, need not be recalculated if the surface reflectivity or illumination changes.

Equation (6) can be solved using the Gauss-Seidel method giving radiation for each area. Tabs can then be calculated from any point of view using conventional visible surface algorithm. Instead of using the surface shading, we can calculate the radiation peak of radiation spots that we can use interpolation shading.

Cohen and Greenberg proposed the following method for the distribution of intensities of emission peaks. If the point is internal to the surface, he is assigned the average radiation from the radiation spots, which are divided on this point. If the point on the edge, then find the nearest internal point $v$. Top marginal radiation when averaged with BV should be the average radiation spots, sharing the

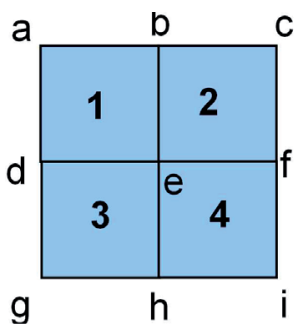

Fig. 2: Elementary surface area of the object.

top edge.

Consider the flats Fig. 2. Radiation to the internal edge e $\mathrm{B}_{\mathrm{e}}=\left(\mathrm{B}_{1}+\mathrm{B}_{2}+\mathrm{B}_{3}+\mathrm{B}_{4}\right) / 4$. Radiation to the top edge $b$ is calculated by finding the nearest internal peak e taking into account that $b$ is the shared areas and a second Therefore, the calculation will use the following definition $\left(\mathrm{B}_{\mathrm{b}}+\mathrm{B}_{\mathrm{e}}\right) / 2=\left(\mathrm{B}_{1}+\mathrm{B}_{2}\right) / 2$.

The solution to get $\mathrm{Bb}$ is $\mathrm{B}_{\mathrm{b}}=\mathrm{B}_{1}+\mathrm{B}_{2}-\mathrm{B}_{\mathrm{e}}$. Internal peak closest to the peak and the peak is also ea very top and the first part of the area Therefore, since $\left(\mathrm{B}+\mathrm{B}_{\mathrm{e}}\right) / 2=\mathrm{B}_{1}$, we get for $\mathrm{B}=2 \mathrm{~B}_{1}-\mathrm{B}_{\mathrm{e}}$. Radiation for other peaks are calculated similarly (Cohen et al., 1985).

The first radiation method was used by Goral (Goral et al., 1984), who used the contour integrals to calculate the form factor for the environment without absorbed convex surfaces.
In the picture (see Fig. 3) you can see the effects of "color bleeding", caused by diffuse reflection between adjacent surfaces, visible in the model in image rendering. Diffuse surface impurities are colors that are reflected by other diffuse surfaces. To become a partial radiological methods, they had to

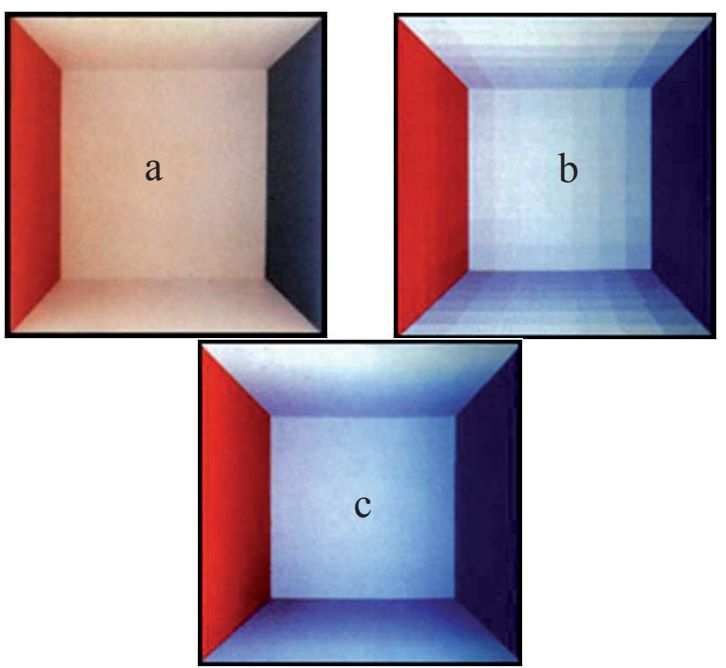

Fig. 3: a-original cube with six sides (front, not shown), we want to model, $b$-rendered image with 49 flats, using the constant shadow, c-rendered image with 49 flats, using the interpolation shading.

start form factors to calculate absorbed surfaces.

\section{Form-factor Calculation}

To find the form factor we must find the fractional contribution that a single patch makes upon another patch. This term is purely geometric, related only to the size, orientation, distance and visibility between the two patches. The basic geometry for form factor calculation is shown in Fig. 4. If we look at Fig. 5 we see that the area $A$ is related to the projected area, $\mathrm{A}_{\mathrm{p}^{\prime}}$ by $\mathrm{A}_{\mathrm{p}}=\mathrm{A} \cdot \cos _{\mathrm{q}^{\prime}}$ and the contribution of a projected area $\mathrm{A}_{\mathrm{p}}$ is related to the solid angle by

$\omega=\frac{A_{p}}{r^{2}}$

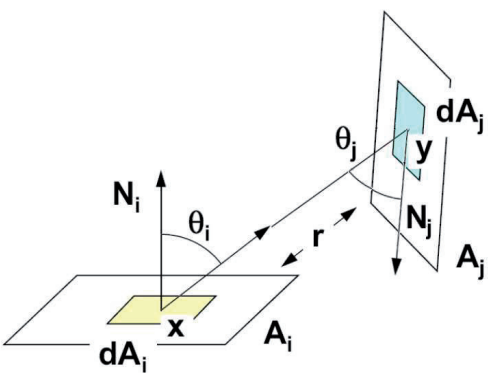

Fig. 4: Form-factor geometry. 


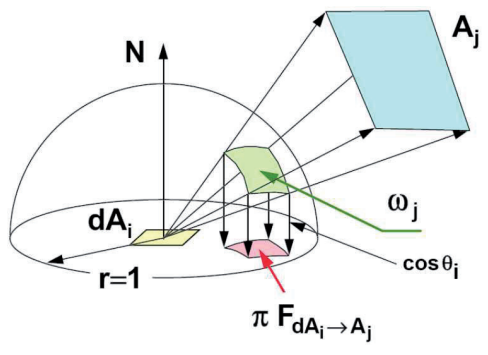

Fig. 5: Projected area onto hemisphere.

The expression relating the contribution from one infinitesimal area to another is:

$F_{d A_{i}-d A_{j}}=\frac{\cos \phi_{i} \cdot \cos \phi_{j} \cdot d A_{j}}{\pi \cdot r^{2}}$

The contribution from an infinitesimal area to a finite area is found by integrating over the receiving area:

$F_{d A_{i}-d A_{j}}=\int_{A_{j}} \frac{\cos \phi_{i} \cdot \cos \phi_{j} \cdot d A_{j}}{\pi \cdot r^{2}}$

And from a finite patch to another finite patch, we take the area average of the previous equation:

$$
F_{d A_{i}-d A_{j}}=\frac{1}{A_{i}} \iint_{A_{i} A_{j}} \frac{\cos \phi_{i} \cdot \cos \phi_{j} \cdot d A_{j}}{\pi \cdot r^{2}}
$$

There are several different methods for evaluating this integral. The contour integral is found by transforming the double integral with Stoke's Theorem (Goral et al., 1984):

$F_{d A_{i}-d A_{j}}=\frac{1}{A_{i}} \iint_{A_{i} A_{j}}\left(\begin{array}{l}\ln (r) d x_{i} \cdot d y_{j}+ \\ \ln (r) d y_{i} \cdot d x_{j}+ \\ \ln (r) d z_{i} d z_{j}\end{array}\right)$

where $\ln (\boldsymbol{r})$ is the intensity for a particular wavelength. One limitation of this algorithm is that it doesn't take into account the visibility between one patch and another, another is that it is extremely expensive computationally. Baum (Baum et al., 1990) also use an analytical approach to find form factors. They integrate the outer integral numerically, while integrating the inner integral analytically by converting it into a contour integral. They then calculate the contour integral by piecewise summation, from Fig. 6.
$F_{d A_{j} A_{i}}=\frac{1}{2 . \pi} \sum_{g \in G_{i}} N_{j} \cdot \Gamma_{g}$

where: $G_{i}$ is the set of edges in surface $i, N_{j}$ is the surface normal for the differential surface $j, \Gamma_{g}$ is a vector with magnitude equal to the angle gamma illustrated in Fig. 4 and direction given by the cross product of vectors $\mathrm{R}_{\mathrm{g}}$ and $\mathrm{R}_{\mathrm{g}+1}$.

Baum use this approach when evaluation by the more efficient hemi-cube method of evaluation described in the following sub-section is geometrically inappropriate for form factor evaluation. They also incorporate an extra term to account for the visibility between surfaces (Baum et al., 1990).

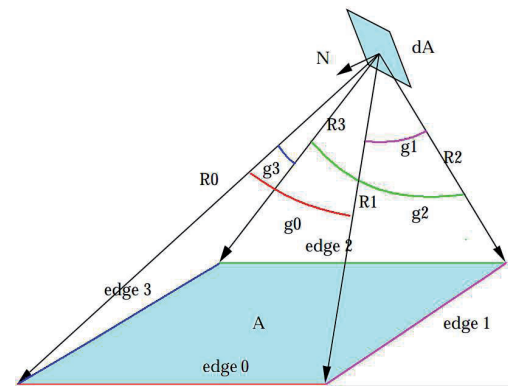

Fig. 6: Geometry for contour integral.

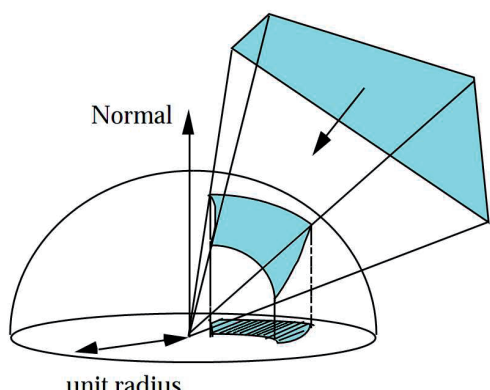

Fig. 7: Nusselt's Analog.

\subsection{Hemi-cube evaluation}

The hemi-cube approach for evaluating form factors was introduced by Cohen (Cohen et al., 1985). It is motivated by examining the geometry in Nusselt's Analog shown in Fig. 7. First, a patch is projected onto the hemisphere surrounding a patch. This projection accounts for the cosine of the angle between the normal of the projected patch and the hemisphere as well as one $1 / r$ term. This projected patch is now projected onto the base of the hemisphere accounting for another $1 / \mathrm{r}$ and cosine term. The area at the base is equivalent to the form fac- 
tor. Many areas are identical to the projected area on the hemisphere, and several of these lend themselves to calculation in a more straightforward fashion. see Fig. 8.

Instead of projecting the environment onto a hemisphere, a cube is placed with the receiving patch at the center (see Fig. 9) and each surface of the cube is divided into a set number of pixels. The contribution of each pixel on the cube's surface to the form factor value can be recalculated since it is only dependent on the pixel location and orientation. The environment is then projected onto the faces of the cube (and half faces). Object visibility can be determined by using simple z-buffer techniques.

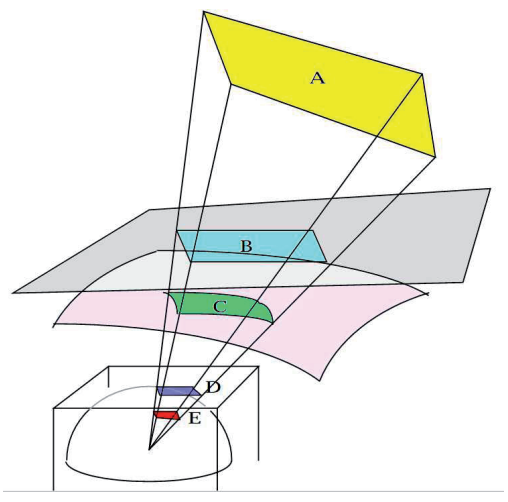

Fig. 8: $A, B, C, D$ \& E all have same form factor.

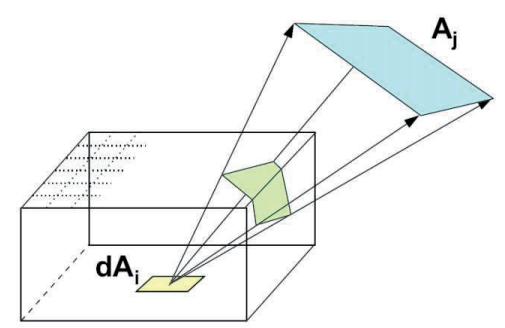

Fig. 9: The hemi-cube project.

After determining which patch is visible at each pixel on the hemi-cube, the sum of all the delta form-factors for each pixel occupied by that patch determines the overall form-factor from the patch at the center of the cube.

Two primary problems exist with the hemi-cube formulation (Fig.10).

- Since only the integral over the sending patch is performed, inaccuracies can occur if the size of the patch is large relative to the distance between the patches. This problem can be alleviated by averaging the results of several hemicubes distributed over the receiving patch or by subdividing the environment into smaller patches or by using the contour integral method discussed above.

- A second problem exists because the hemi-cube samples the environment at regularly spaced solid angles, thus aliasing problems can occur. Small patches in the environment might never be seen while others may only be sampled by one or two hemi-cube grid cells. One solution to solving these problems is to use a different visibility algorithm; ray tracing.

\subsection{Raytracing for finding Form Factors}

Using ray tracing to find form factors has a number of attractions. First, since ray tracing can be done adaptively and stochastically, many of the aliasing problems in hemicubes can be overcome.

Second, raytracing can handle a wide variety of geometries so that the objects which act as the "masks" need not be discretized into patches and the original geometries for the objects may be used. Although raytracing is not easily implemented in silicon, a number of acceleration techniques have been found for raytracing and in fact, for complicated scenes, algorithms have been found that actually perform better than the software z-buffers (Fujimoto et al., 1986). Finally, ray tracing techniques can play an important role for the inclusion of specular effects.
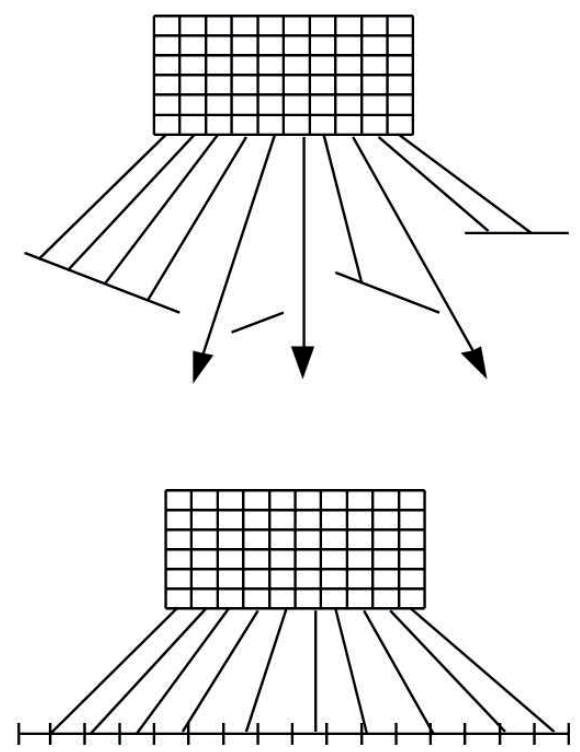

Fig. 10: Aliasing problems of the hemi-cube. 


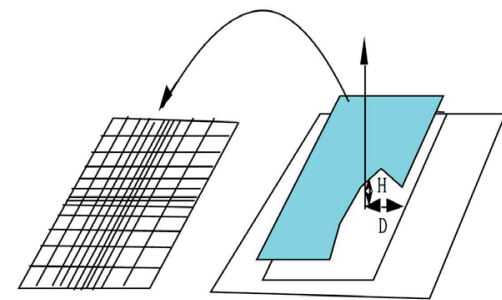

Fig. 11: Sillion's proxels for form factors.

Sillion used a hybrid approach between hemicubes and ray tracing by placing a plane close to a receiving patch and sampling a rectangular grid on that plane centered about the patch (Fig. 11). Some light is lost beyond the edges of the rectangular grid, but that amount can be made arbitrarily small by adjusting the distance of the plane from the patch. The grid is divided up into uneven elements (called proxels - projection elements) based on each elements contribution to the form factor and visibility is calculated by Warnock's algorithm. Once the patch visibility is calculated from each window, the contribution number of proxels is summed and the form factor is calculated. Raytracing is then used on the corners of the window to verify that it has been subdivided properly, and for the generation of extended form factors (Silion et al., 1989).

One straightforward approach in using raytracing (actually ray casting since only object visibility information is used), is to sample the hemisphere around a patch uniformly in all directions. However doing so wastes effort by sampling areas that do not contribute a great deal. Directions close to the normal will have a large effect while those at the periphery a smaller effect. Malley uses this method by jittering a number of samples in a distribution about the normal.

Another way of using ray tracing for form factor calculation was used by Wallace in (Wallace et al., 1989). Here, instead of computing the entire environments contribution to a single patch, the computation is turned around and the contribution of a single patch to every differential area in the environment is found. Essentially a patch is divided into a number of smaller regions $\triangle \mathrm{A}$ 's and each region is sampled by a ray from some point in the environment. In other words, radiosity equation is discretized and calculated for each subregion:

$F_{d A_{i}-A_{j}}=\sum_{k=1}^{n} \frac{\cos \varphi_{i k} \cdot \cos \varphi_{j k}}{\pi \cdot r^{2}} \Delta A_{j}$
This however still does not overcome the problem when $\triangle \mathrm{A}$ is large relative to $\mathrm{r}^{2}$. To do so, one can discrete the environment into ever smaller patches, or treat the $\triangle \mathrm{A}$ 's as finite areas and use an analytical expression between a differential area and a finite area to sum the form factors (Fig. 12).

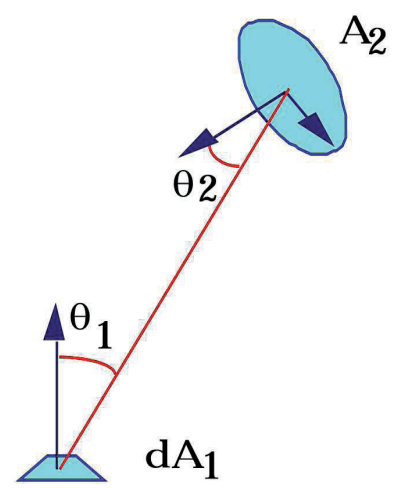

Fig. 12: Differential area to disk form-factor.

If each $\triangle \mathrm{A}$ is considered to be a small disk of area $\mathrm{A}_{2}$ the form factor from a differential area to a directly opposing disk of area $\mathrm{A}_{2}$ is:

$F_{d A_{i}-A_{j}}=\frac{A_{2}}{\pi \cdot r^{2}+A_{2}}$

Taking into account the relative orientations of the source and receiving areas makes:

$F_{d A_{i}-A_{j}}=\frac{A_{2} \cos \varphi_{i} \cdot \cos \varphi_{j}}{\pi \cdot r^{2}+A_{2}}$

and finally if a patch of area $\mathrm{A}_{2}$ is subdivided into $\mathrm{n}$ delta areas:

$F_{d A_{i}-A_{j}}=\frac{A_{2}}{n} \sum_{k=1}^{n} \frac{\cos \varphi_{i k} \cdot \cos \varphi_{j k}}{\pi \cdot r^{2}+A_{2}}$

\section{Aplication Outputs}

Currently, the development of computer graphics software products exist to enable a comprehensive design and calculation of parameters of lighting systems, which would reflect light effects that arise in artificial and day lighting.

The computer programs will be able to calculate and visualize the daylight, lighting scenes, plan the color and intensity of the lights, position on the project the emergency lighting, with the right legal 
number of luminaires, prepare photo realistic visualizations of light planning. The furniture, surfaces and luminaires can be placed simple dragging and dropping elements from the provided libraries. For a better realism, the programs can use different textures and furniture, and it uses an integrated ray tracing or radiosity module.

Computer graphics is the field of visual computing, where one utilizes computers both to generate visual images synthetically and to integrate or alter visual and spatial information sampled from the real world. The computer visualization, which goal is to see the photo, is often described in detail of the model and simulates the propagation of light in space. Modern visualization programs can reproduce the brightness, color and surface structure of the complex three-dimensional space rather realistic, since in the calculations include inter reflection of light between surfaces in space and in many optical effects arising in the day, an artificial joint or lighting.

In consequence, the market appeared to be several light-technical programs with different purposes and uses. In principle, computer programs can be divided into two basic groups (Smola et al., 2005):

- calculation programs - the result include lighting parameters (Dialux, Relux, Europic, Calculux, WinLuxus, Wils a pod.),

- visualization programs - the result include visualization - the figures of lighting (3D Studio, Catia,

\section{AutoCAD, LightScape, Corel Photo-Paint a i.).}

These programs are designed for light-technical parameters calculation and on the presentation of projects and usualy offers the following program modules for lighting design:

- Interior lighting, utilisation factor method,

- Interior lighting, point by point calculation,

- Interior lighting, direct glare (UGR calculation),

- Interior lighting, glare by reflection on visual display terminals,

\section{- Exterior lighting, area lifting,}

\section{- Exterior lighting, street lighting.}

For purposes of this contribution to the possibilities of simulation outputs in the DIALux 4.7 (Fig.13). This simulation program offers the following options selected lighting system and various options for presentation of results as graph values, isolines maps, light maps - colour scale, false colour rendering, summary tables of lighting respectively brightness, three-dimensional model lighting respectively, brightness economic evaluation of the lighting project in terms of energy consumption, visualization of sunshine and so on (Kevická, 2009).

Fig. 14 shows isoline maps, which display equal values of illuminance measured in the vicinity of a luminaire. With DIALux the user has the option to display the $3 D$ rendering in a false colour rendering presentation (Fig.15). The presentation of illuminance and luminance with freely scalable value ranges and definable colour gradients is now available.

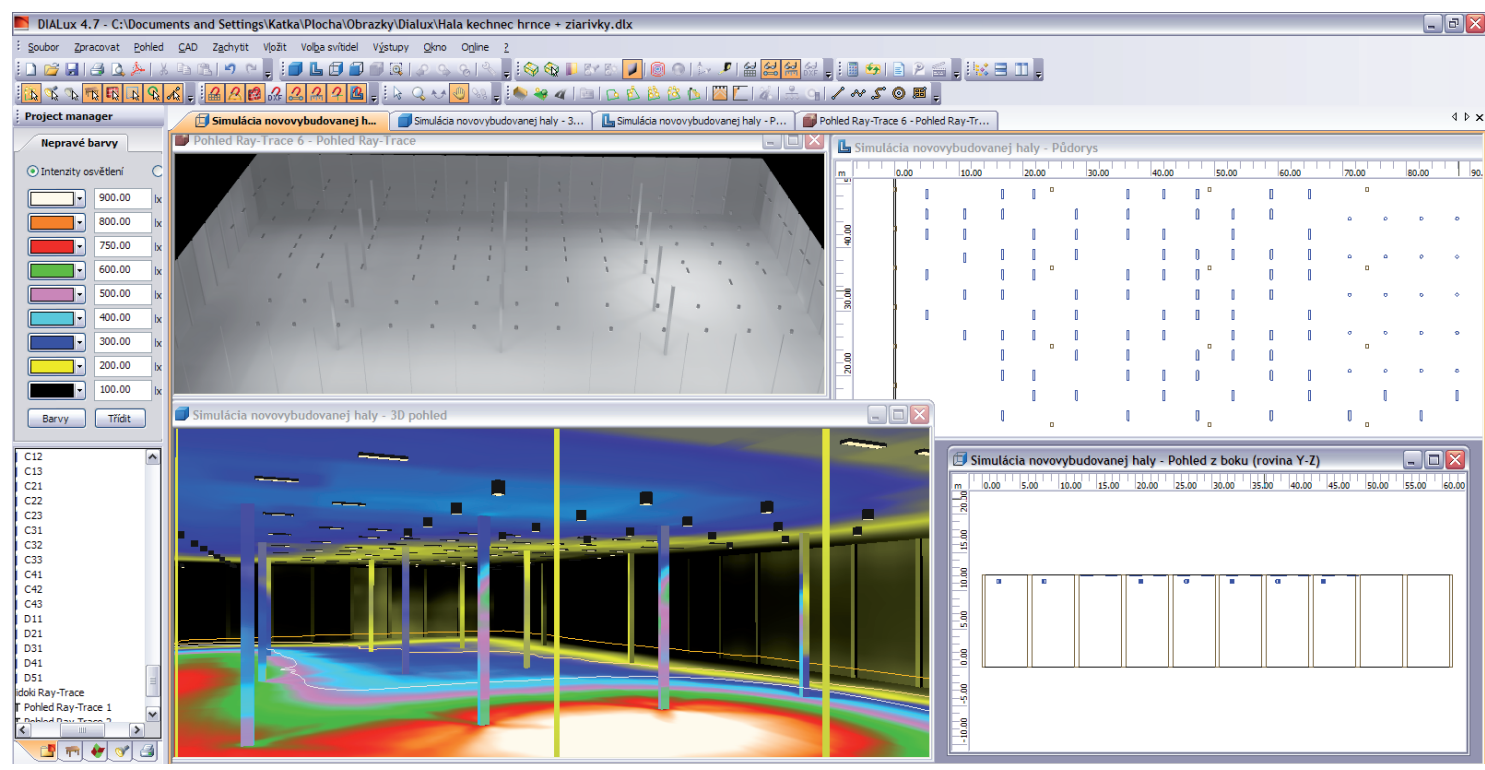

Fig. 13: Display of DIALUX 4.7 

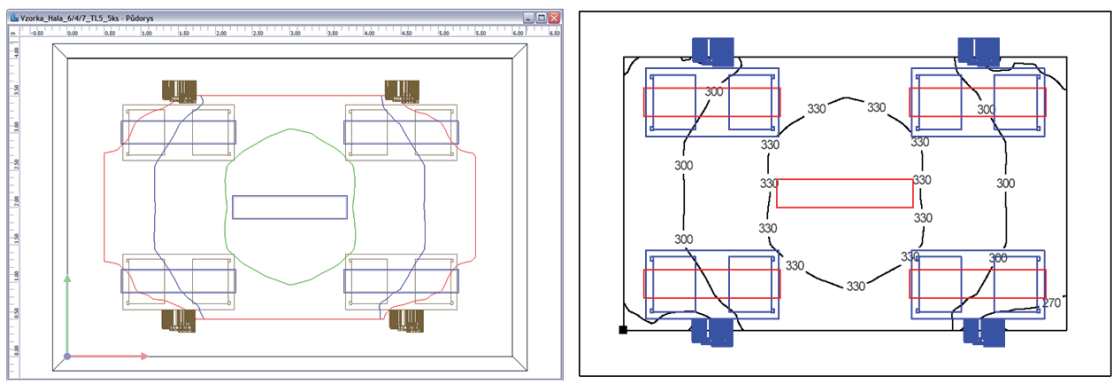

Fig. 14: Isoline map.

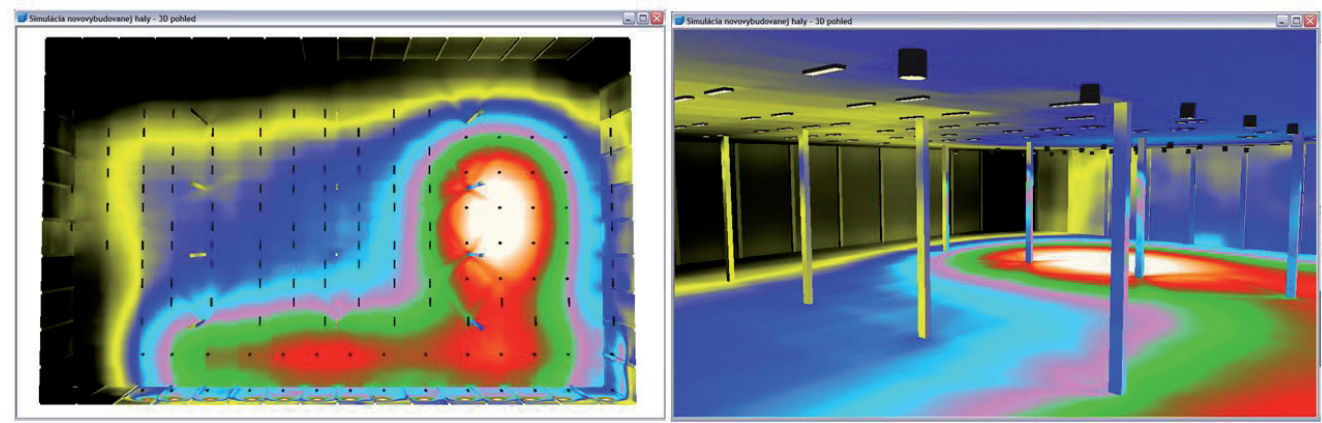

Fig. 15: 3D rendering in a false colour rendering presentation.

On the Fig. 16 is 3D Light distribution curve, (LDC). This function is useful to check the correct placement of luminaires with asymmetrical distribution. Figure 17 shows layout of false colour rendering and detail of light distribution curve.

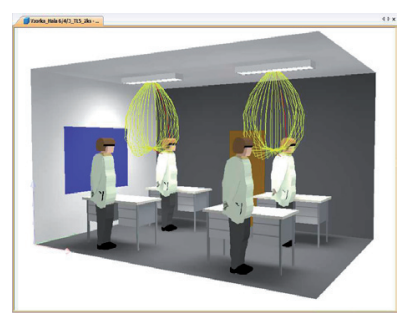

Fig. 16: Detail of light distribution curve (LDC).

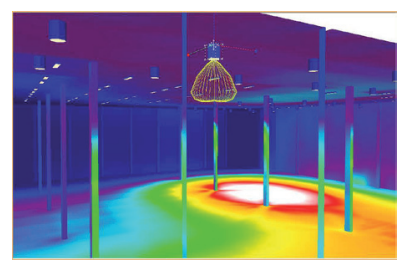

Fig. 17: Layout of false colour rendering and detail of LDC.

\section{Conclusion}

In terms of quantity of information a person registers on the job $80 \%$ to $95 \%$ of all the information visually. Primary role in creating the work environment becomes so ensure optimal conditions of vision and ensure a safe working environment. Visibility must therefore be seen as a precondition for the realization of high quality, safe and reliable operation work. This issue is necessary to pay close attention. Just when dealing with light-technical projects is a useful visualization tool lighting parameters using realistic lighting display parameters.

\section{Acknowledgement}

This contribution was elaborated within the project KEGA No 3/7426/09 Physical factors of environment - valuation and assessment" and KEGA No 3/7422/09 Creating of research conditions for preparation of modern university text book"Ecodesign in Mechanical engineering".

\section{References}

[1] Baum, D.R. \& Winget, J.M. (1990). Real Time Radiosity through Parallel Processing and Hardware Acceleration. Computer Graphics (Special Issue on 1990 Symposium on Interactive 3D Computer Graphics, vol. 24/2, p. 67-75, (March, 1990)

[2] Budak, V. P.; Makarov, D., N. \& Smirnov, P., A. (2006). Přehled a porovnání počítačových programů pro navrhování osvětlovacích soustav, SVETLO 1/2006, vol.1, No.1/2006, 
p.50-54, ISSN 1212-0812

[3] Chen, S. E.; Rushmeier, H. ; Miller, G. \& Turner, D. (1991) A progressive multi- pass method for global illumination, Computer Graphics, vol. 25/4, July 1991, p. 165- 174

[4] Cohen, M. F. \& Greenberg D. P.(1985). The hemi cube: A radiosity solution for complex environments. Symposium on Computational Geometry, p. 31 - 40, (July 1985)

[5] Fujiomoto, A; Tanaka, T. \& Iwata, K., (1986). ARTS Accelerated Ray Tracing System, IEEE C.G. \& A. ,vol 6 (4), p. 16-26 (April 1986)

[6] Gašparovský, D; Pazdera, M., (2011). Porovnanie vypočítaných a nameraných hodnôt intenzity osvetlenia v interiérech, In. Slovalux 2011, SSTS Bratislava, KONGRES management s.r.o., pp. 71-80, ISBN 978-80-89275-28-1

[7] Goral, C.M.; Torrance, K..E.; Greenberg, D.P. \& Battaile, B. (1984). Modeling the interaction of light between diffuse surfaces. Computer Graphics, 18(3), vol. 18/3 p.213-222, July 1984

[8] Klvač, P (2008). Logický postup při navrhování vnitřního umělého osvětlení, SVĚTLO 06/2008, vol.6, No.6/, ISSN 1212 0812

[9] Rybár, P. et al. (2001) Denní osvětlení a oslunění budov, ERA group spol.s r.o., Brno, 2001, ISBN 80-86517-33-0, Brno, Czech Republic

[10] Sillion, F. \& Puech, C. (1989). A General Two-Pass Method Integration Specular and Diffuse Reflection. Computer Graphics, vol. 23(3):p. 335-344, July 1989, Boston.

[11] Silion, F. \& Puech, C. (1994) Radiosity and Global Illumination, Morgan Kaufmann, 1994

[12] Smola, A. (2003) Osvetlenie priemyselných hál, In: AT\&P Journal 3/2003, vol.3, No.3/2003, ISSN 1336-5010

[13] Smola, A.; Gašparovský, D. \& Krasňan, F. (2005). Navrhovanie vonkajšieho a vnútorného osvetlenia $v$ nadväznosti na technické normy a právne predpisy, SAP, Bratislava, 2005, ISBN 80-89104-71-1, Bratislava, Slovakia

[14] Wallace, J.R.; Elmquist, K.A. \& Haines, E.A (1989). A raytracing algorithm for progressive radiosity, Computer Graphics, vol. 23(3): p.315-324, July 1989, Boston. 